Supporting Information

\title{
Interactions of OSW-1 with lipid bilayers in comparison with digitonin and soyasaponin
}

Raymond Malabed, Shinya Hanashima, Michio Murata, Kaori Sakurai 


\section{Time-course leakage assay}

Time-course calcein leakage experiments were conducted for digitonin, OSW-1, and soyasaponin $\mathrm{Bb}(\mathrm{I})$. Since it was observed that a higher amount of soyasaponin $\mathrm{Bb}(\mathrm{I})$ was required to induce $50 \%$ leakage, $300 \mu \mathrm{M}$ concentration was also used to estimate the $\mathrm{EC}_{50}$ values at varying phospholipid concentrations (Fig. S3). [S1, S2]
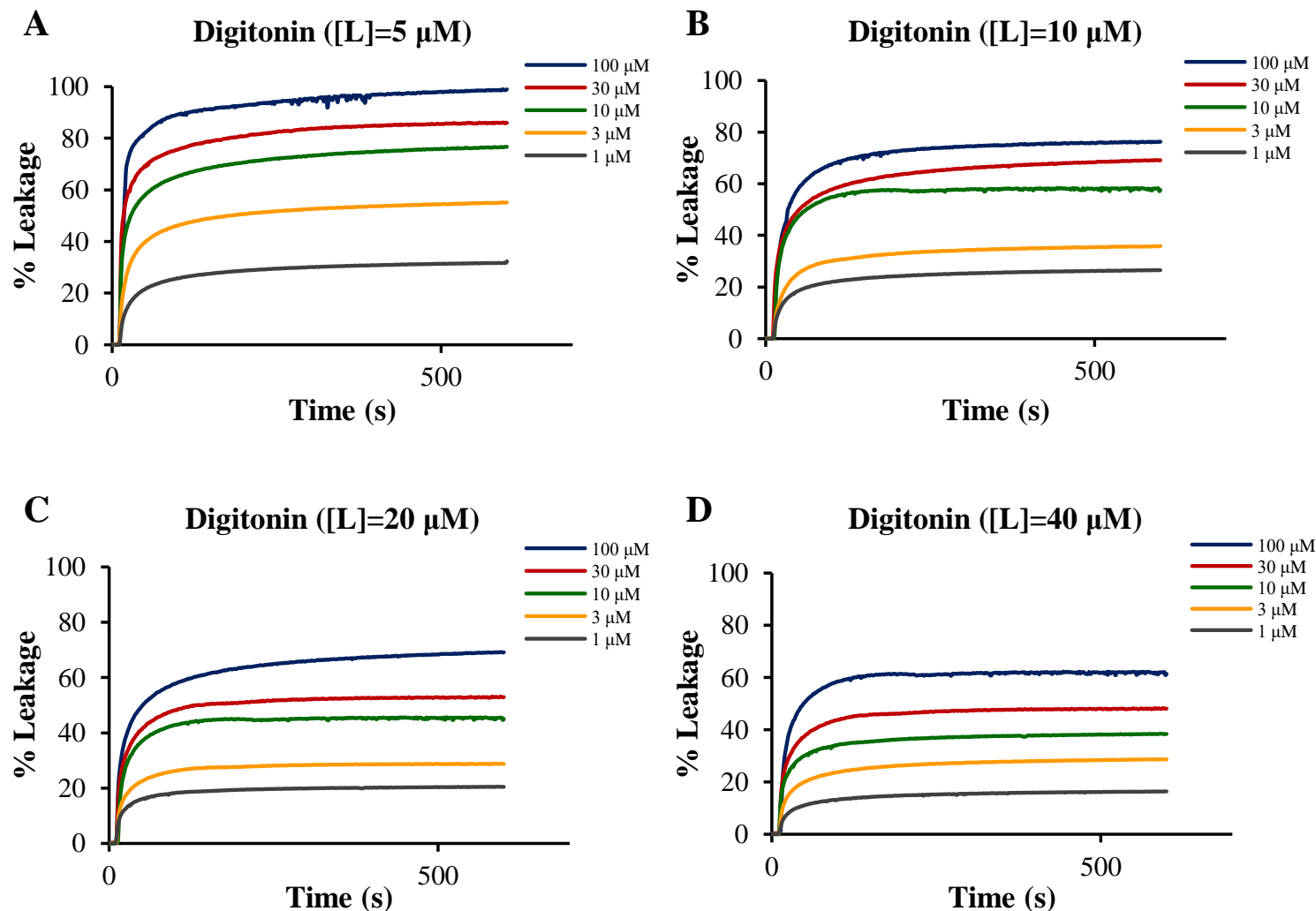

Figure S1. Time-course calcein leakages caused by treatment with digitonin in POPC:Chol (9:1) LUVs $(\mathrm{A}=5 \mu \mathrm{M}, \mathrm{B}=10 \mu \mathrm{M}, \mathrm{C}=20 \mu \mathrm{M}, \mathrm{D}=40 \mu \mathrm{M}) .100 \%$ leakage was obtained by the addition of $10 \%(\mathrm{v} / \mathrm{v})$ Triton X-100. All experiments were performed at $25{ }^{\circ} \mathrm{C}$. 

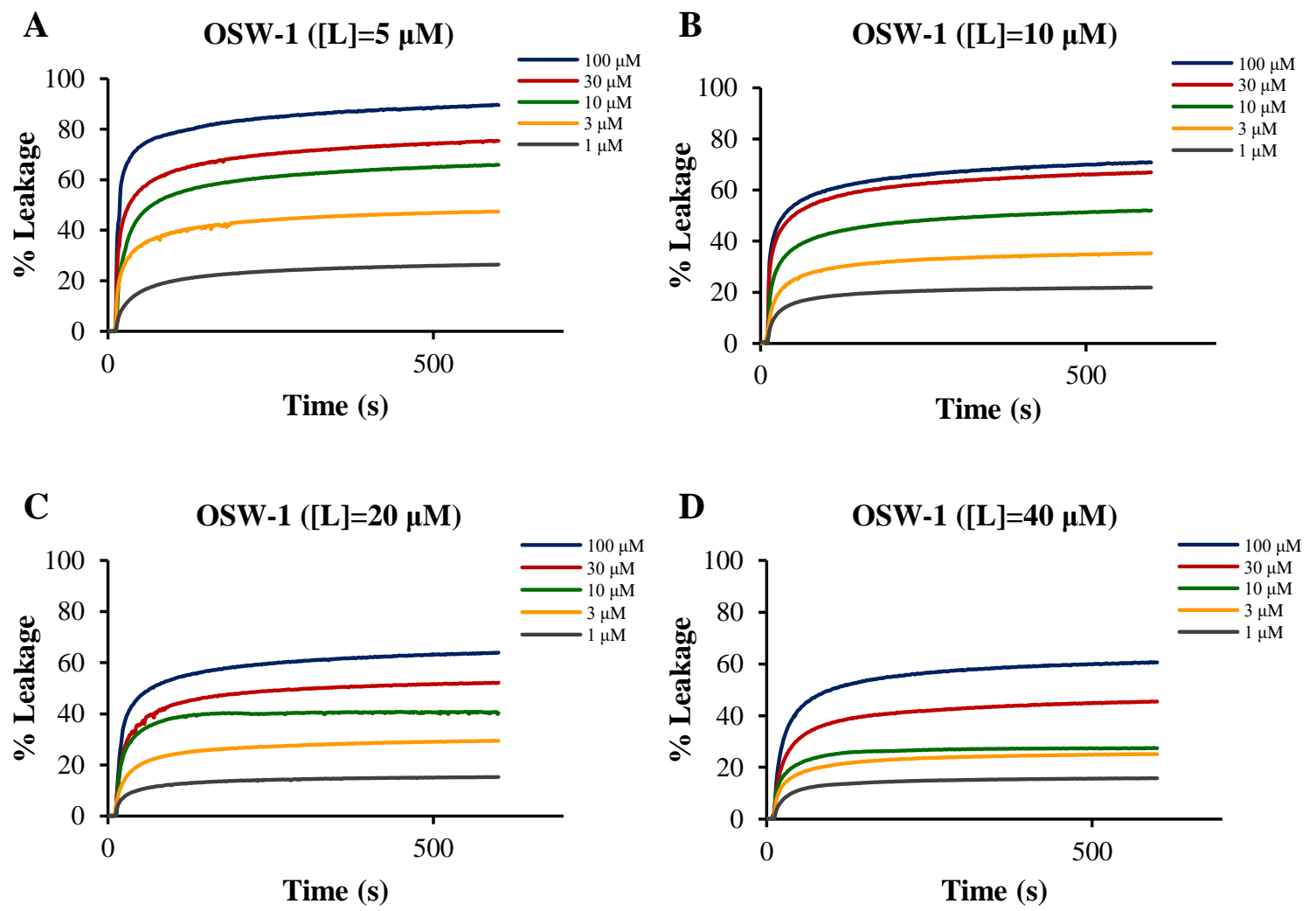

Figure S2. Time-course calcein leakage by treatment with OSW-1 in POPC:Chol (9:1) LUVs (A $=5 \mu \mathrm{M}, \mathrm{B}=10 \mu \mathrm{M}, \mathrm{C}=20 \mu \mathrm{M}, \mathrm{D}=40 \mu \mathrm{M}) .100 \%$ leakage was obtained by addition of $10 \%$ (v/v) Triton X-100. All experiments were performed at $25^{\circ} \mathrm{C}$. 

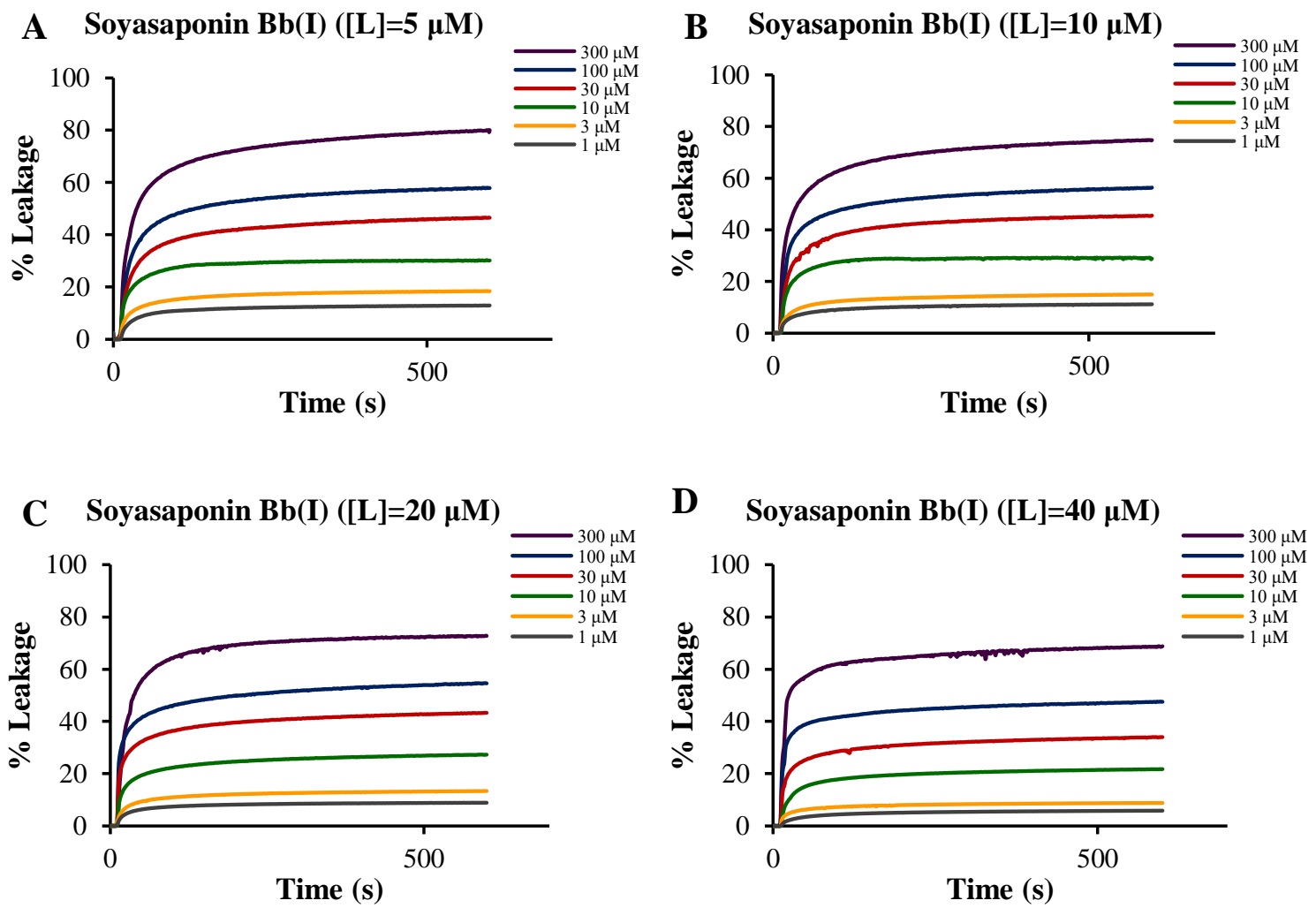

Figure S3. Time-course calcein leakage by treatment with soyasaponin Bb(I) in POPC:Chol (9:1) LUVs $(\mathrm{A} ; 5 \mu \mathrm{M}, \mathrm{B} ; 10 \mu \mathrm{M}, \mathrm{C} ; 20 \mu \mathrm{M}, \mathrm{D} ; 40 \mu \mathrm{M}) .100 \%$ leakage was obtained by addition of $10 \%(\mathrm{v} / \mathrm{v})$ Triton X-100. All experiments were performed at $25{ }^{\circ} \mathrm{C}$. 
Concentration-response curves for each saponins in POPC-Chol 9:1 LUVs

The concentration-response curve was also plotted for different concentrations of total lipids as shown in Figure S4. This was used to determine the concentration of saponin needed to induce leakage percentages from 5\% to $60 \%$ taken at the vertical axis separately.
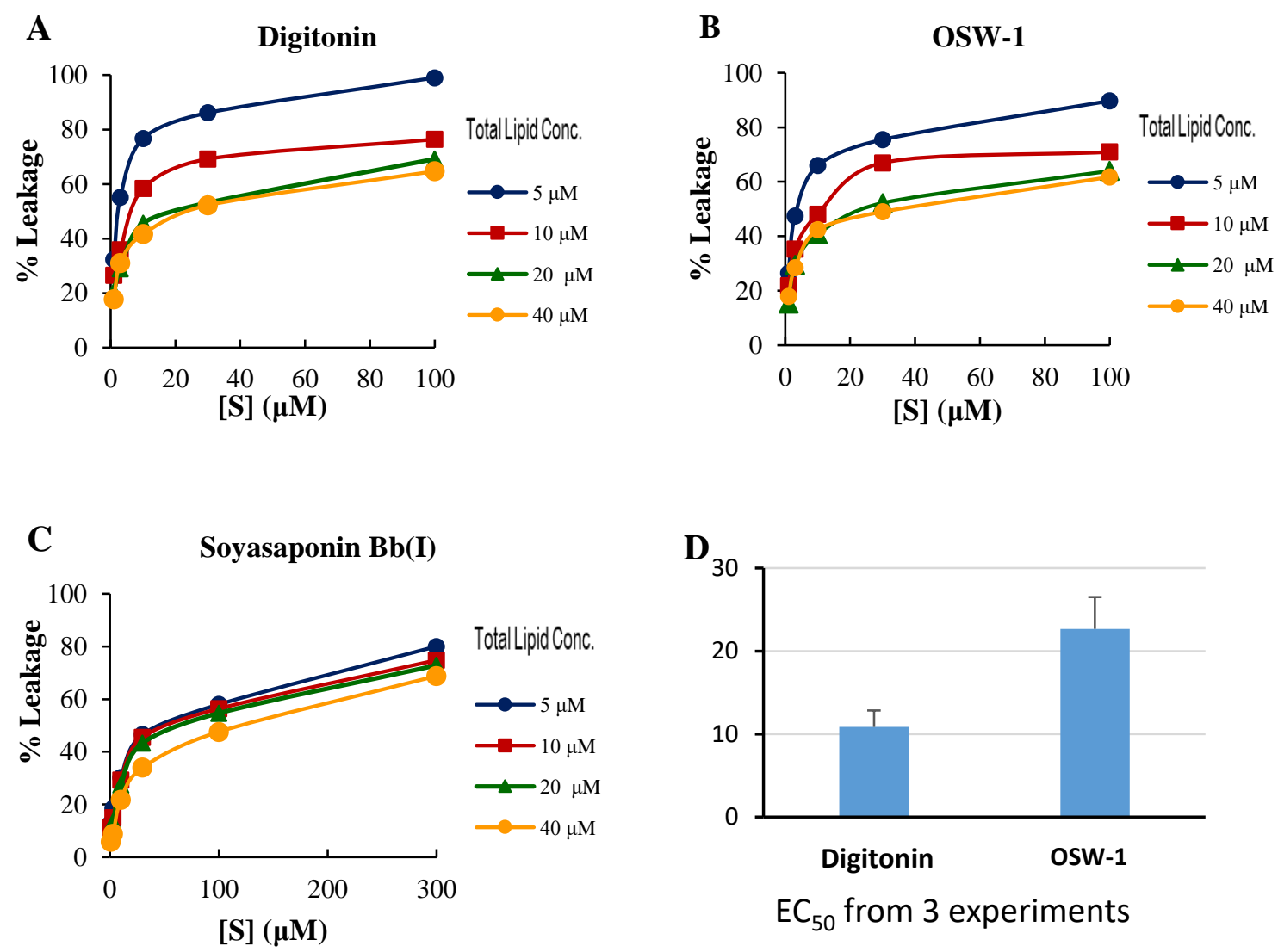

Figure S4. Concentration-response curves for digitonin (A), OSW-1 (B), and soyasaponin Bb(I) (C) for POPC:Chol (9:1) LUVs at the incubation time of 10 min. (D) Average $\mathrm{EC}_{50}$ and standard error values for digitonin $(10.9 \pm 2.0 \mu \mathrm{M})$ and OSW-1 $(22.7 \pm 3.8 \mu \mathrm{M})$ were obtained from three independent binding isotherm experiments with $30 \mu \mathrm{M}$ POPC:Chol (9:1) LUVs.

Determination of the apparent affinity constant $K_{\text {app }}$

The saponin lipid binding in the n:1 binding ratio between saponins and lipids was expressed as follows: 


$$
\mathrm{n}[S]_{f}+[L]_{f} \leftrightarrow[n S \cdot L]
$$

where $[\mathrm{S}]_{\mathrm{f}}$ and $[\mathrm{L}]_{\mathrm{f}}$ are the concentrations of saponins and lipids in a free state, and $[\mathrm{nS} \cdot \mathrm{L}]$ is

the concentration of the saponin-lipid complex. Thus, Ka could be expressed as follows:

$$
K_{a p p}=\frac{[n S \cdot L]}{\left([S]_{f}\right)^{n}[L]_{f}}=\frac{\frac{[S]_{b}}{n}}{\left([S]_{f}\right)^{n}\left([L]-\frac{[S]_{b}}{n}\right)}=\frac{\frac{r[L]}{n}}{\left([S]_{f}\right)^{n}\left([L]-\frac{r[L]}{n}\right)}=\frac{\frac{r}{n}}{\left([S]_{f}\right)^{n}\left(1-\frac{r}{n}\right)}
$$

The transformations are achieved by using following equations.

$$
\begin{gathered}
{[L]_{f}=[L]-[L]_{b}=[L]-[n S \cdot L]} \\
{[S]_{b}=n \times[n S \cdot L]} \\
r=\frac{[S]_{b}}{[L]}
\end{gathered}
$$

where $[\mathrm{L}]$ and $[\mathrm{L}]_{\mathrm{b}}$ are the total and bond lipid concentrations, and $[\mathrm{S}]_{\mathrm{b}}$ is the bond saponin concentration. Finally, $r$ could be expressed as follows:

$$
r=\frac{n K_{a p p}\left[S_{f}\right]^{n}}{1+K_{a p p}\left[S_{f}\right]^{n}}
$$

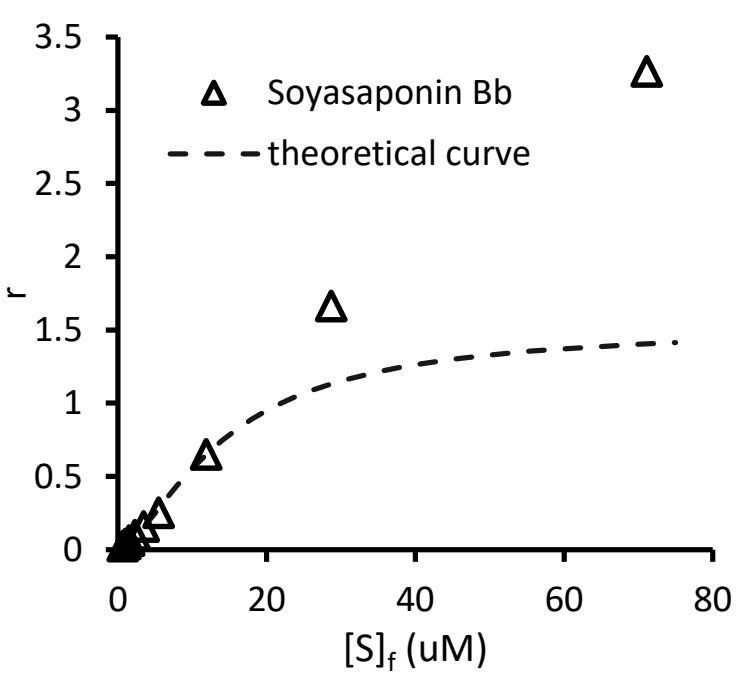


Figure S5. Binding isotherms of soyasaponin $\mathrm{Bb}(\mathrm{I})$ at different leakage percentages for POPC:Chol (9:1) LUVs. The bound saponin/lipid ratio $(r)$ was plotted for each free saponin concentration $[\mathrm{S}]_{\mathrm{f}}$. The theoretical curves from equation 3 were shown in broken traces.

Concentration-response curves for each saponins with LUVs of different Chol contents

Without Chol
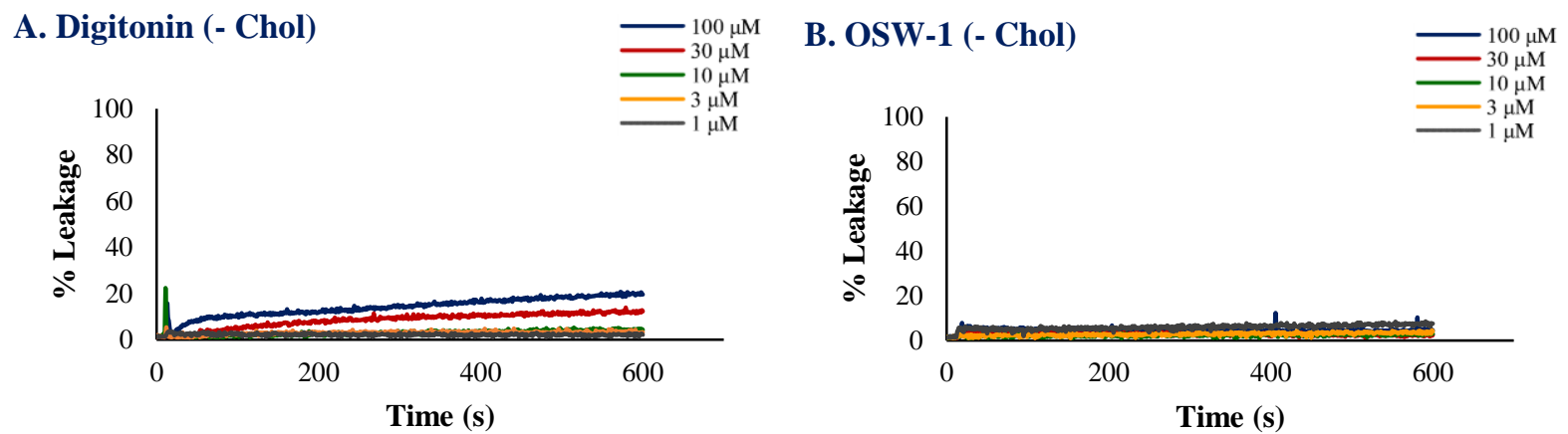

Figure S6. Time-course calcein leakage for pure POPC.

With $10 \%$ Chol
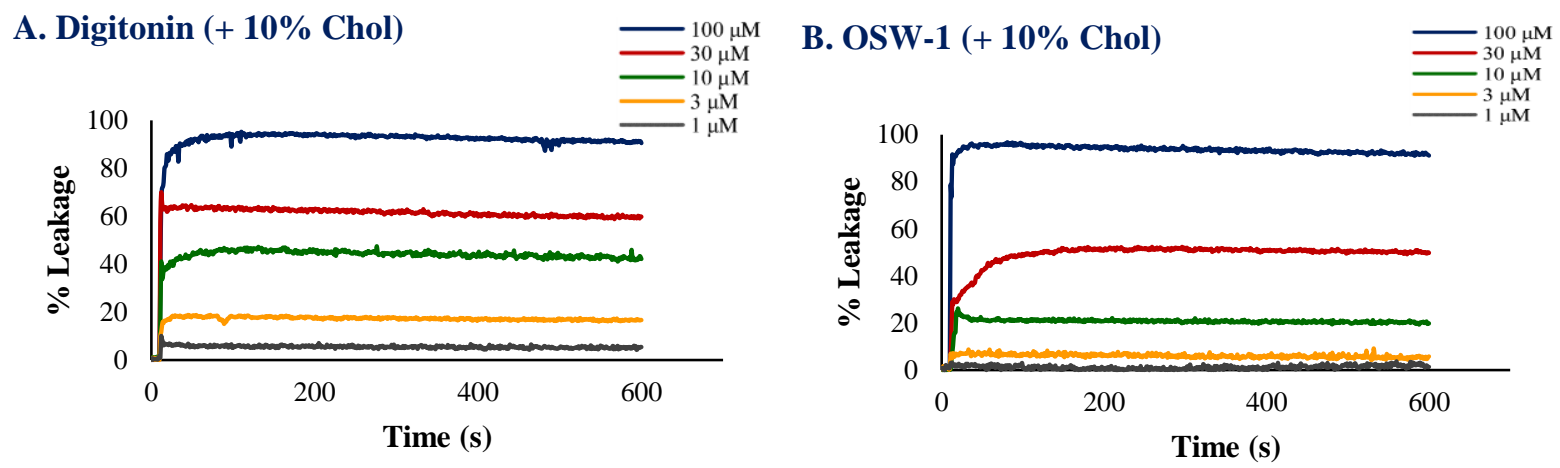

Figure S7. Time-course calcein leakage for $10 \%$ Chol-containing POPC.

With 5\% Chol 

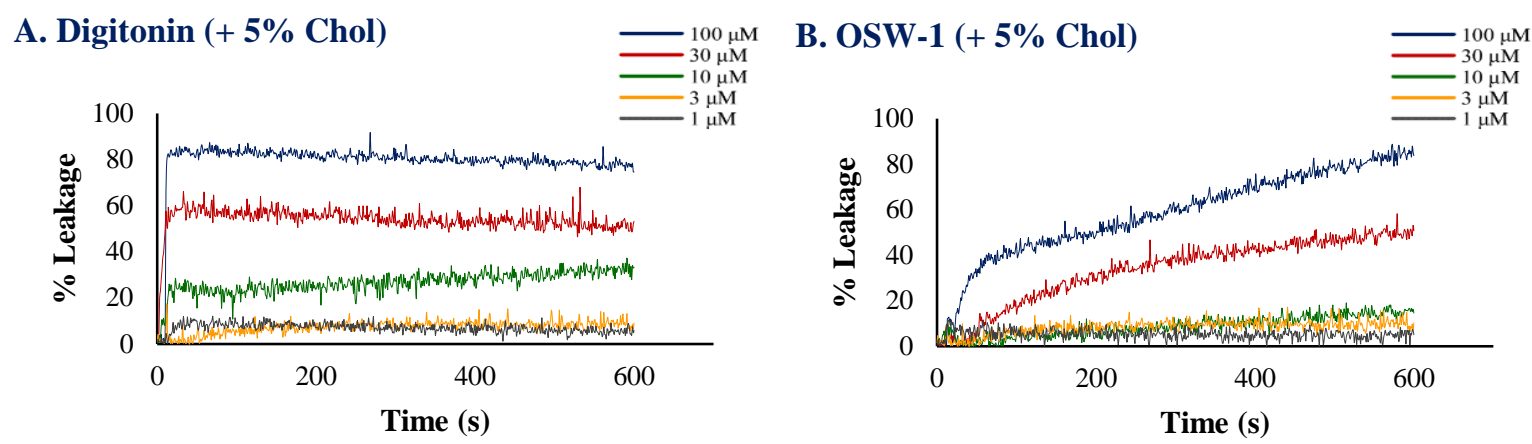

Figure S8. Time-course calcein leakage for 5\% Chol-containing POPC.

\section{With $20 \%$ Chol}

A. Digitonin (+ 20\% Chol)

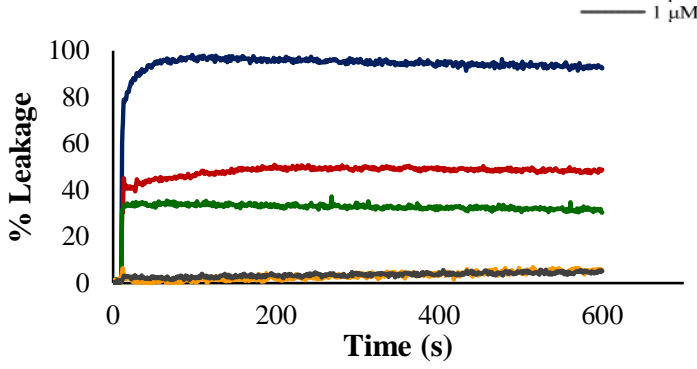

B. OSW-1 (+ 20\% Chol)

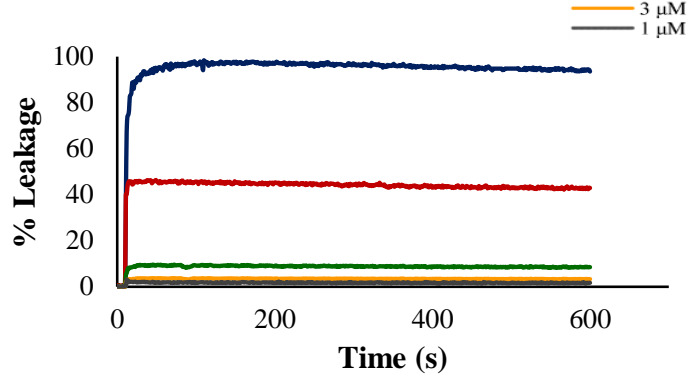

Figure S9. Time-course calcein leakage for $20 \%$ Chol-containing POPC. 

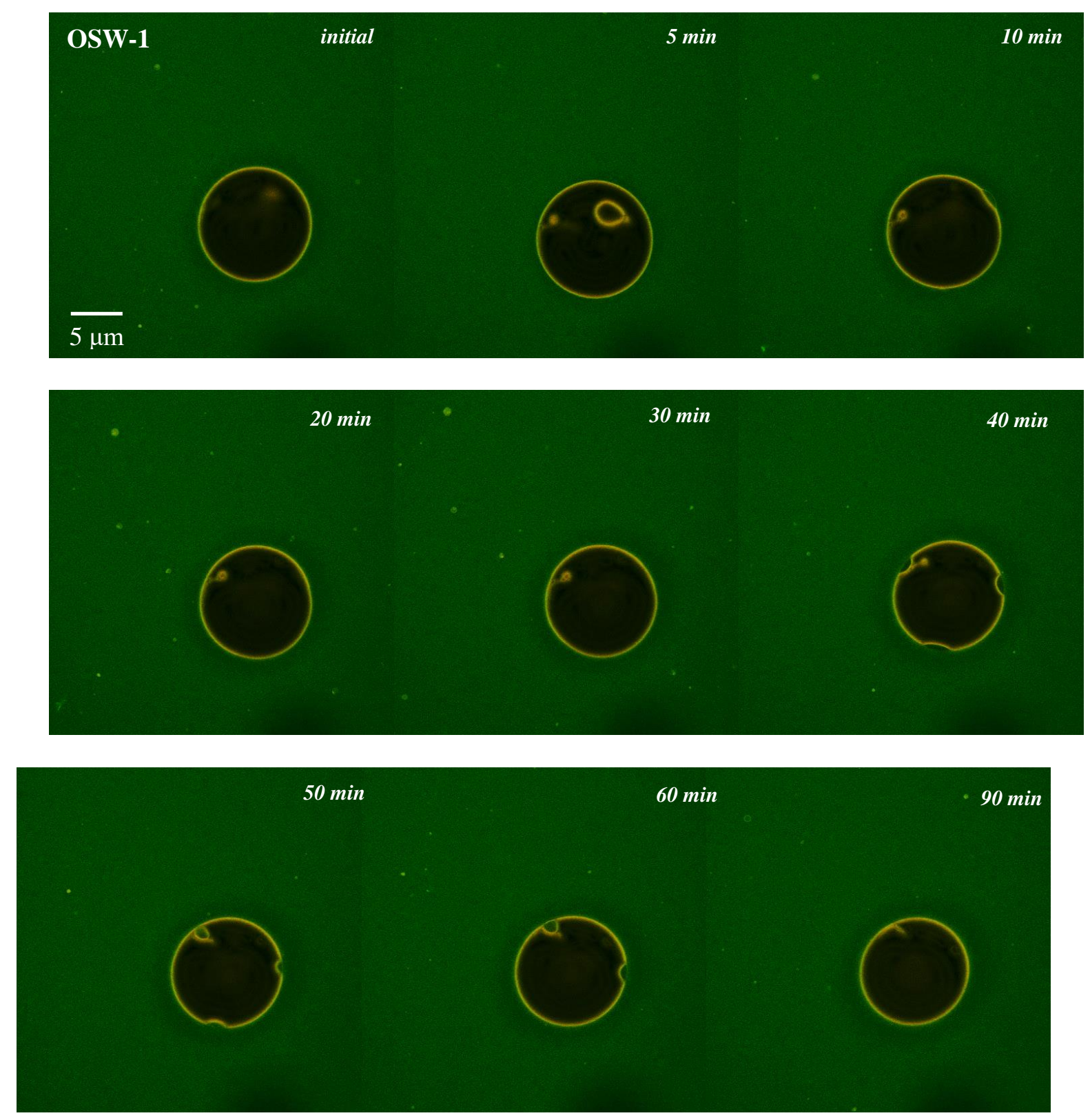

Figure S10. Effect of $30 \mu \mathrm{M}$ OSW-1 on membrane morphology as examined by confocal microscopy partially shown in Fig. 7. Observations were conducted for 90 minutes after the addition of $30 \mu \mathrm{M}$ OSW-1. The GUVs were composed of POPC:Chol (9:1) labelled with 0.01 mol\% DiI, while the extravesicular solution was labelled with 0.01 mol\% rhodamine $6 \mathrm{G}$. The final concentrations of POPC and Chol were $75 \mu \mathrm{M}$ and $8.5 \mu \mathrm{M}$, respectively. Scale bar: $5 \mu \mathrm{m}$. 

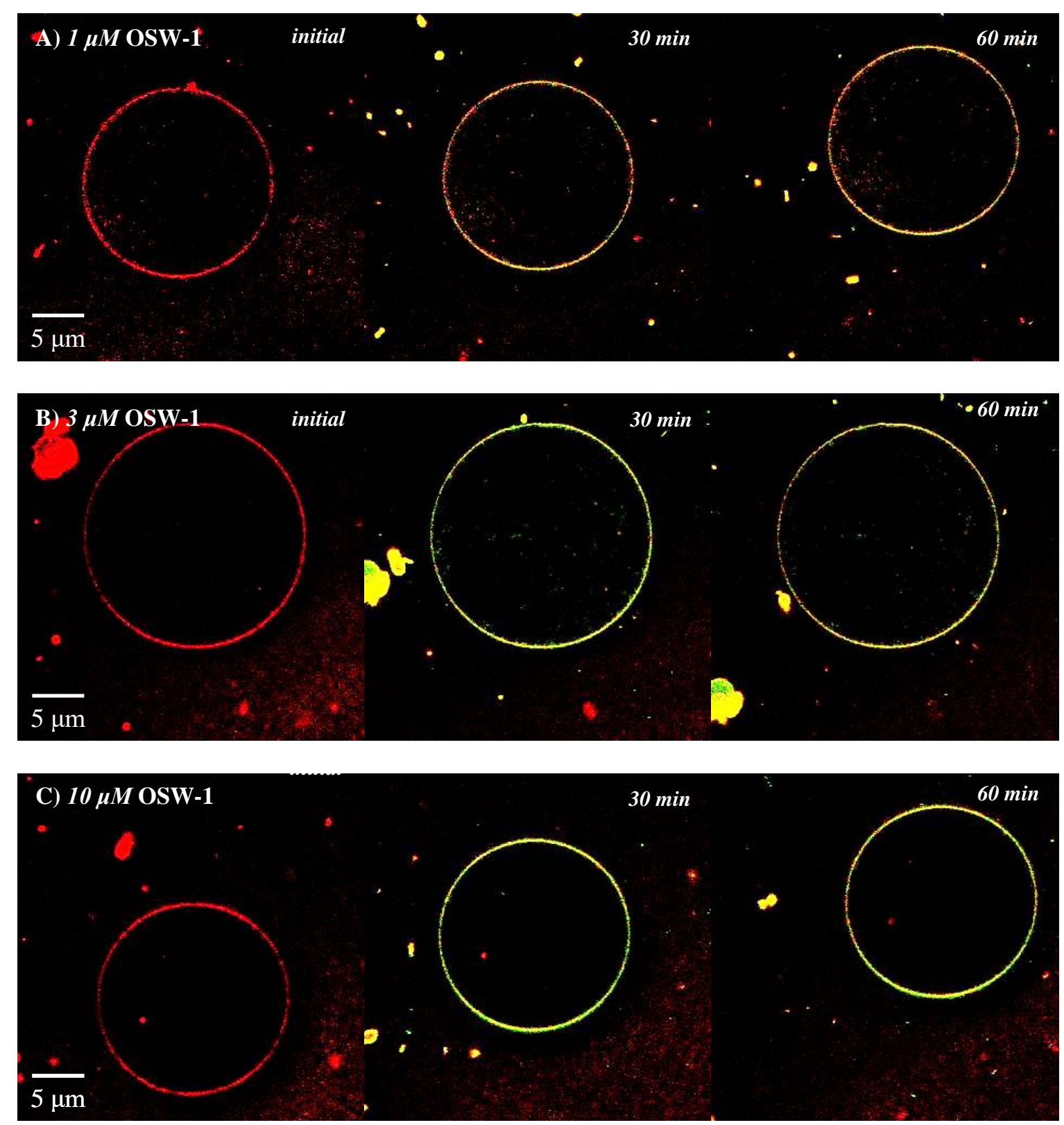

Figure S11. Effect of various OSW-1 concentrations on membrane morphology as examined using confocal microscopy. Observations were conducted for $60 \mathrm{~min}$ after the addition of OSW1. The GUVs were composed of POPC:Chol (9:1) labelled with $0.05 \mathrm{~mol} \%$ TR-DPPE (in the initial flames). The final concentrations of POPC and Chol were $75 \mu \mathrm{M}$ and $8.5 \mu \mathrm{M}$, respectively. OSW-1 was mixed with $1 \mu \mathrm{M}$ DBD-OSW-1 to give a characteristic fluorescence property. The 
vesicles shown in the $30 \mathrm{~min}$ and $60 \mathrm{~min}$ flames are the composite images of TR-DPPE (red) and DBS-OSW-1 (green). Scale bar: $5 \mu \mathrm{m}$.

\section{References}

[S1] Hu, M.; Konoki, K.; Tachibana, K. Cholesterol-independent membrane disruption caused by triterpenoid saponins. Biochim. Biophys. Acta 1996, 1299, 252-258.

[S2] Ohnishi, Y.; Tachibana, K. Synthesis of pavoninin-1, a shark repellent substance, and its structural analogues toward mechanistic studies on their membrane perturbation. Biorg. Med. Chem. 1997, 5, 2251-2265. 